\title{
A integração nacional pelo saneamento do sertão: Goiás no relatório de Arthur Neiva e Belizário pena (1912)
}

The national integration due the backcountry sanitation : Goiás report by Arthur Neiva

and Belisário Penna (1912)

\section{Vera Lúcia Caixeta}

Doutora em História Professora da Universidade Federal de Tocantins caixeta@uol.com.br

\begin{abstract}
Resumo: Trata-se da investigação sobre a proposta de saneamento do sertão, dos médicos Arthur Neiva e Belisário Neiva, do Instituto Oswaldo Cruz, elaborada a partir da viagem científica ao norte do país, em 1912. Para a análise recorreu-se tanto a concepção de temporalidade como pensada por Koselleck, quanto ao conceito de civilização de Norbert Elias, além da concepção de campo e de poder simbólico de Bourdieu. O saneamento do sertão proposto médicos sanitaristas seria a chave para a integração nacional, a qual retiraria o sertanejo do abandono, do atraso, da fome, do analfabetismo e da doença a que estavam relegados. Enfim, buscou-se colocar em questão as narrativas elaboradas sobre a população do interior de Goiás, a partir de uma maneira de ver as coisas específicas de um local, de uma época, de um "campo" que mobiliza valores e imagens.
\end{abstract}

Palavras-chave: Saneamento do sertão, relatório Neiva e Penna, Goiás.
Abstract: This article is about the investigation into the backcountry sanitation proposal, made by the doctors Arthur Neiva e Belisário Neiva, part of the Oswaldo Cruz Institute, elaborated based on their scientific trip to the north of the country in 1912. For the analysis, the conception of temporality as thought by Koseleck and the concept of civilization of Norbert Elias were both used, beyond the conception of knowledge field and symbolic power by Bourdieu. The sanitation of the backcountry proposed by the sanitarian doctors would be the key to national integration, which would withdraw the backlanders of abandonment, backwardness, hunger, illiteracy and disease they were been relegated. Finally, the narratives produced about the population in the interior of Goiás were called into question, from a way of seeing the specifics of a place, a time, a "knowledge field" that mobilizes values and images.

Keywords: The backcountry Sanitation, Neiva and Penna report, Goiás. 


\section{Introdução}

Quase todos os domicílios, em todo o trajeto, ofereciam todas as condições para permitir a reprodução das triatomas; a maioria é constituída por casas de adobe, não rebocadas [...] (Neiva e Penna, 1999, p.100-101)

Em Goiás o Estado do Brasil, certamente o mais flagelado pela moléstia de Chagas. (Neiva e Penna, 1999, p.120)

A miséria assume proporções dolorosas, é nas regiões baianas e piauienses próximas a Goiás e principalmente no norte deste Estado, onde grande número de brasileiros vive ao Deus dará, procurando mel o comendo o que caça sem sal, cozido simplesmente n'agua e acompanhado de arroz, quando há, farinha e alguns cocos quando é tempo. (Neiva e Penna, 1999, p.164)

[...] em Goiás o analfabetismo ainda é maior e não estará longe da verdade quem o calcular pelo menos em 95\%. (Neiva e Penna, 1999, p.170)

[...] a organização da família legalmente não existe pois, só por exceção, os casais se unem pelo casamento civil; os filhos quase nunca são registrados (NEIVA \& PENNA, 1999: 180).

Entre os desafios de todo o pesquisador, está o de pensar na construção de um objeto viável com uma razoável quantidade de fontes acessíveis. Como uma viagem, a pesquisa exigiu tomada de decisões sobre o melhor caminho a seguir, o que levar em consideração, o que necessariamente deixar em vista dos objetivos e dos procedimentos a serem utilizados para alcançá-los. Colocar-se a caminho é arriscar-se "controladamente". 1 O desafio aqui enfrentado foi o de investigar a proposta de saneamento do sertão, dos médicos Arthur Neiva e Belisário Neiva, do Instituto Oswaldo Cruz, elaborada a partir da viagem científica ao norte do país, em 1912.

O fio condutor que direcionou a análise foi o relatório Neiva e Penna no livro Viagem científica pelo norte da Bahia, sudoeste de Pernambuco, sul do Piauí e de norte a sul de Goiás, em 1918. ${ }^{2}$ Ele forneceu "as mais fortes imagens associadas às viagens

\footnotetext{
${ }^{1}$ Como já ensinou Certeau, "Em história, tudo começa com o gesto de separar, de reunir, de transformar em 'documentos' certos objetos distribuídos de outra maneira. Esta nova distribuição cultural é o primeiro trabalho". Ao produzir os documentos, o historiador muda ao mesmo tempo o seu lugar e o seu estatuto, já que "desfigura", "isola" e forma a "coleção" a ser trabalhada. Ver: CERTEAU, 2000: 81.

${ }^{2} \mathrm{O}$ relatório e todo o material produzido durante a viagem de Neiva e Penna foi publicado em livro. Ele está organizado em duas partes: o relatório propriamente dito e o diário de viagem. A publicação de Neiva e Penna foi reproduzida em uma edição fac-similar, lançada pelo Senado Federal em 1999, no qual me baseei para a realização da análise proposta. Além do relatório e do diário de viagem, foram publicadas como anexos mais de cem fotografias (116 no total) e um encarte com um mapa do Brasil, no qual é indicado o roteiro percorrido pela expedição. No final, estão as biografias dos referidos cientistas. A experiência da viagem, da qual resulta o registro narrativo e visual (fotográfico), são formas de dizer o mundo, de explicar, interpretar e significar o real.
} 
científicas do Instituto Oswaldo Cruz" (LIMA, 1999: 86). Expedições científicas foram enviadas aos vários recantos do país, no início da Primeira República (1889-1930). ${ }^{3}$ Nenhuma delas causou tanto impacto, seja nos intelectuais ou nos políticos da época, quanto o relatório Neiva e Penna. Ali apareceu o interior do país como exemplo dramático de pobreza, da doença e da decadência, a síntese do Brasil rural, doente e abandonado (SÁ, 1999). Um Brasil que, certamente, clamava pela integração nacional. ${ }^{4}$

$\mathrm{Na}$ "tecitura" dessa trama fez-se necessário conhecer melhor as experiências e expectativas de Neiva e Penna. ${ }^{5}$ Coloquei em questão as narrativas elaboradas sobre a população do interior, a partir de uma maneira de ver as coisas específicas de um local, de uma época, de um "campo" que mobiliza valores e imagens. Ao compreender a história como um discurso construído sobre os homens, fruto do trabalho de historiadores inseridos no seu tempo e dentro das suas condições de produção, negou-se a impossibilidade de uma produção objetiva do passado. ${ }^{6}$

Paulo Sérgio Moreyra, num pequeno opúsculo intitulado "o olho que vê o mundo", do final da década de 1980 ressaltou a necessidade de análise do olhar do naturalista francês Saint-Hilaire que viu Goiás, em 1819. Já que a visão e a compreensão são mediadas por uma distância, "coberta por sua visão européia" (MOREYRA, 1988, p.164). Diva Muniz, ao tratar das narrativas dos viajantes “estrangeiros" pelo interior do Brasil oitocentista afirmou que elas são reveladoras e reiteradoras das fronteiras que separam o Brasil dos brasileiros e os brasileiros entre si "em razão das diferenças de classe, raça, etnia, religião, escolaridade, ocupação, domicílio, gênero e região, dentre as principais" (MUNIZ, 2011, p.24).

\footnotetext{
3 Nísia Trindade observou que, desde a sua origem, as atividades de "Manguinhos" não se limitaram ao Distrito Federal, registrando-se, ainda na primeira década, ações sanitárias em vinte e três portos, em São Luiz do Maranhão, no interior do Estado de São Paulo, Minas Gerais e na Baixada Fluminense. Naquele período, foram acentuadas as ações de combate aos surtos epidêmicos de doenças como a febre amarela, a peste bubônica e a varíola. Ver: LIMA, 1999: 79.

${ }^{4}$ Oswaldo Cruz conseguiu dois feitos memoráveis, de acordo com Hochaman: vencer a tradição retórica e clínica da medicina da capital (ao vencer a epidemia da febre amarela no Rio de Janeiro tornou-se o primeiro cientista-herói do país); e a fundação do primeiro instituto científico de reconhecimento internacional: o Instituto Federal de Soroterapia de Manguinhos (fundado em 1901). Sua produção médica se concentrava principalmente sobre duas especialidades: a Saúde Pública e a Higiene. Ver: HOCHMAN, 1998: 217-235. ${ }^{5}$ A concepção de temporalidade proposta por Koselleck passa pelo "espaço de experiência" e de "horizonte de expectativa". É nessa tensão entre o passado vivido, experimentado e o futuro sonhado, desejado e projetado que o presente é configurado "KOSELLECK, 2006: 305-327".

${ }^{6}$ Para Certeau, a história é um discurso controlado por um corpo de enunciados "científicos" e, como tal, se abre à "possibilidade de estabelecer um conjunto de regras que permitem controlar operações proporcionadas à produção de objetos determinados" (CERTEAU, 2000: 68). Também para Le Goff, todo documento é monumento. Logo, se as fontes apresentam vestígios materiais do passado elas também carregam os rastros do imaginário de uma época, de uma sociedade na qual os narradores estão inseridos (LE GOFF, 1996: 525-545).
} 
Para Míriam Leite (1997, p.10), o olhar 'de fora' do grupo visitado por alguém 'de passagem' coloca-o numa situação de observador alerta e privilegiado. Porém, o olhar viajante está mais susceptível a cometer equívocos: “Ao avaliar o grupo visitado e seus valores estranhos, dos quais o observador tem apenas amostras concretas fragmentárias, o visitante e o habitante acabam vítimas de inúmeros mal-entendidos" (1997: 10).

Nesse esforço dos narradores para significar o interior do país, considerei-os como os "porta-vozes autorizados" da sua referida instituição. Para Bourdieu: "o poder das palavras é apenas o poder delegado do porta-voz cujas palavras (...) constituem no máximo um testemunho, um testemunho entre outros da garantia da delegação de que ele está investido" (2008: 87). O narrador representa uma delegação, fala em nome de um grupo, "comanda o acesso que lhe abre a língua da instituição, à palavra oficial, ortodoxa, legítima” (BOURDIEU, 2008: 87). Assim, a eficácia dos discursos dos referidos médicos passa tanto pela capacidade daquele que o pronuncia quanto pelo prestígio da instituição que os autorizam a pronunciá-los.

As diferentes significações, designações e atribuições de sentido dadas aos goianos são orientadas por alguns princípios e um deles é o da “civilização" e, consequentemente, o seu oposto, a barbárie. ${ }^{7}$ No caso do Brasil, como ressaltou Janaína Amado (1995: 145-146), desde o período colonial surgiu nos núcleos urbanos fixados no litoral, o espaço do estabelecimento das instituições colonizadoras constituídos como espaço da civilização em oposição aos outros espaços sociais. Essa dicotomia referente aos espaços litoral/sertão orientou a leitura dos viajantes estrangeiros e nacionais que percorreram o interior do Brasil. Mais do que em oposição à região de litoral, foi em contraste com a ideia de "região colonial" que seu significado se constituiu. O espaço preenchido pelo colonizador representava o mundo da ordem, estabelecido pela Igreja e pelo Estado, em oposição surgiu o sertão: o território vazio, o desconhecido, o espaço não colonizado (MELLO, 1987).

Nísia Trindade Lima, ao retomar a ideia de sertão, presente entre os intelectuais da geração 1870, como Euclides da Cunha, Vicente Licínio Cardoso, Roquete Pinto,

\footnotetext{
${ }^{7}$ Para Norbert Elias, a noção de "civilização" se liga "a dados variados: ao grau de evolução técnica, às regras do saber-viver, ao desenvolvimento do conhecimento científico, às ideias e usos". Para os franceses e ingleses, essa noção resume "o orgulho da nação, progresso do Ocidente e da humanidade em geral", nesse sentido, "civilização" expressa "a consciência ocidental, se poderia dizer, o sentimento nacional ocidental". Porém, a noção de "civilização" apaga até certo ponto as diferenças entre os povos, pois coloca em ênfase aquilo que é comum a todos os homens. Já no caso dos alemães, eles exprimem o orgulho de suas civilizações e de sua própria natureza, através da noção de "cultura", é ela que "reflete a consciência de uma nação". Enquanto a noção de "civilização" se liga à ideia de processo, de expansionismo, de conquista; a noção de "cultura" remete a um sentido de limites, de "interno" (ELIAS, 1994: 23).
} 
Belisário Penna, Monteiro Lobato, entre outros, ressaltou que eles atualizaram a leitura dualista da realidade brasileira e perceberam-no como espaço simbólico. Em Euclides da Cunha, os sertões estavam marcados pela distância cultural de "três séculos" que os separavam do litoral. Lima identificou ainda uma continuidade temática voltada para a “incorporação dos sertões” entre os intelectuais da Primeira República e aqueles após a institucionalização das ciências sociais no país, no pós-1930. Ela encontrou em autores como Alberto Torres, Oliveira Viana, Gilberto Freyre e Gilberto Amado a ênfase nos contrastes entre litoral e sertão (LIMA, 1999). Sertão significava a distância com relação ao poder público e aos projetos modernizadores (LIMA, 1999).

Nicolau Sevcenko (2003: 45) percebeu que no início da Primeira Repúbica (18891930) quando a cidade do Rio de Janeiro passou pela "Regeneração", conduzida pelo sanitarista Oswaldo Cruz, ela ganhou estatuto de cidade moderna, exaltou o orgulho do brasileiro do litoral e redimiu-o do estigma da preguiça atribuída pelos estrangeiros. Porém, essa redenção só era válida para as grandes cidades, pois, "Antes de ir para a gaveta, o chavão ainda seria esgrimido pelos autores que escreveram sobre as sociedades rurais e os grupos tradicionais. Aliás, mais do que nunca, agora se abusaria da oposição cidade industriosa / campo indolente". Naquele momento, a produção intelectual aprofundou "a idéia do desmembramento da comunidade brasileira em duas sociedades antagônicas e dessintonizadas, devendo uma inevitavelmente prevalecer sobre a outra, ou encontrarem um ponto de ajustamento" (SEVCENKO, 2003: 45).

Significativamente, a Primeira República (1889-1930) é marcada por um intenso debate em torno de um projeto para a nação. O foco das discussões centra-se na necessidade de conhecer os brasileiros do interior e construir uma nação imaginada. Expedições científicas, como a comandada pelos médicos Arthur Neiva e Belisário Penna, avaliam as condições epidemiológicas, sua relação com as condições de vida e do trabalho das populações locais e procuram comprovar a tese de Carlos Chagas de que a doença descoberta e divulgada ao mundo em 1909 está generalizada pelo interior do país. Percebe-se, enfim, que, para os médicos/cientistas, a tarefa a que se impõem é enorme: revelar o "verdadeiro" Brasil aos brasileiros e apontar os caminhos para a construção da nação. 


\section{O purgatório goiano nas narrativas de Arthur Neiva e Belizário pena}

Em todo o longo percurso [de Porto Nacional a capital de Goiás], apenas três núcleos de população. -Descoberto, Amaro Leite e Pilar, extremamente decadentes, com suas populações, na totalidade constituídas de negros mestiços, inutilizada pelo terrível flajelo que é a moléstia de Chagas, não atingindo nenhuma delas a 400 habitantes.

Neiva e Penna, 1999, p.220

[...] guardamos vivas, as impressões bem tristes, da profunda miséria e do abandono em que jazem milhares de seres humanos e, o nosso depoimento, de forma alguma viria mitigar as suas aflições (NEIVA \& PENNA, 1999: 165).

Questão clássica da historiografia desde Heródoto, Hartog (1999) enfatiza na sua tese o fato fundamental do exílio e da viagem para a prática historiográfica. Hartog chama atenção para as figuras que são mobilizadas pelo narrador para fazer a enunciação do outro, a um destinatário familiar, já que "entre o narrador e o destinatário existe, como condição para tornar possível a comunicação, um conjunto de saberes sistêmicos, enciclopédicos e simbólicos que lhes é comum” (1999: 49). Assim, o narrador vai movimentando com as figuras, seja para persuadir, enunciar, comparar, classificar ou, por fim, para excluir o outro.

A presença física dos narradores no Brasil central permite a mensuração dos espaços percorridos, além de estabelecer paralelos e comparar as distâncias culturais entre os diferentes espaços sociais. No diário de viagem, é possível acompanhar os percalços enfrentados nos caminhos de mais de sete mil quilômetros, saindo do Rio de Janeiro e percorrendo as regiões norte e nordeste. ${ }^{8}$ A viagem implica estranhamento, Neiva e Penna assinalam o desconforto frente ao abandono em que vivem as populações locais, suas condições "primitivas" de existência: sem escolas, sem estradas, sem polícia, sem cuidados médicos, nem higiênicos. A população sabe da existência do governo apenas pela cobrança de impostos de bezerros, bois, cavalos e burros (NEIVA \& PENNA, 1999: 199). Além disso, eles registram o retrocesso de muitas cidades, além da rotina e da ignorância generalizadas, e concluem que o "povo é indolente, como aliás em todo o Brasil" (NEIVA E PENNA, 1999: 198). Porém, logo eles retomam sua tese da doença e do abandono para explicar aquela situação.

\footnotetext{
${ }^{8}$ Nas localidades em que a expedição permaneceu por mais tempo como Juazeiro (17 dias), São Raimundo Nonato (17 dias), Paranaguá (17 dias) e Porto Nacional (12 dias) foram realizados registros com ricas informações sobre o modo de vida dos seus habitantes (NEIVA \& PENNA, 1999).
} 
O dr. Neiva e eu vimos no norte de Goiás, quadros infernais, que só o grande poeta florentino poderia descrever, criando mais um ciclo no seu famoso inferno.

Núcleos de população desde 60 a 300 indivíduos, na sua maioria idiotas, cretinizados, ou alejados ou paralíticos, percorremos nós, onde dificilmente se deparava um semi-idiota capaz de dar algumas ligeiras informações.

Inúmeros lugarejos onde $100 \%$ dos habitantes estavam atacados pelo terrível flagelo nas suas modalidades mais graves (PENNA, 1918: 29).

Percebe-se que o olhar do narrador amplia-se e daí a pouco algumas características encontradas num dado grupo visitado são projetadas para todo o interior do país. Segundo Hartog, "No espaço da narrativa, o olho do narrador [...] recorta as zonas mais ou menos críveis para o destinatário" (1999: 273). As imagens negativas ajudam a criar o efeito de realidade e qualificam o olhar mensurador do narrador. É, portanto, a figura do narrador que estabelece uma relação de persuasão com o leitor, ao afirmar "eu vi" e "eu conheço". Assim, o fato de ter visto, examinado, conversado, por fim, ter usado os "olhos e os ouvidos", contribui para tornar críveis as narrativas de Neiva e Penna, legitimadas por um dos principais institutos científicos da época, o "Oswaldo Cruz".

Para Nicolau Sevcenko (2003, p.96-137), uma das características mais marcantes da tradição intelectual brasileira, na passagem do século XIX para o XX, é o intenso desejo de reinventar a nação. Nesse sentido, os cientistas compreendem a atividade intelectual como missão política ou como 'ação pública', voltada para a reforma e transformação efetiva da realidade brasileira. Tanto Arthur Neiva quanto Belisário Penna são considerados bem-sucedidos nesse esforço obstinado de intervenção para a construção da nação. Eles projetam soluções próprias para os problemas nacionais, rompem com o modismo e a imitação de ideias europeias (SOUZA, 2009: 250). Enfim, eles reinventam a nação ao "fazer ver e fazer crer" que na sua narrativa está a "realidade", a "verdade" do país.

Neiva e Penna afirmam que, se forem escrever um poema para descrever os sertões, ele será um poema trágico. Ele contaria as misérias e as desgraças dos seus habitantes, destruiria toda a poesia do viver no campo, seus encantos, a fartura do solo, a saúde das populações e a generosidade da natureza. Este poema denunciaria o quadro 
infernal, que só poderia ser perfeito se descrito pelo Dante imortal. ${ }^{9}$ Eles fazem questão de ressaltar que ali não se encontram as terras férteis, as matas infindáveis, as inesgotáveis fontes de pedras preciosas, uma raça forte e destemida, nem seus campos seriam cobertos de rebanhos de gado sadio. Enfim, a vida no interior não se aproxima do paraíso, ao contrário, os “ sertões que conhecemos, quer os do extremo norte, quer os centrais quer os do norte de Minas, são pedaços do purgatório, como nol'o pintam os padres, onde se purgam os pecados em vida (...)" (NEIVA \& PENNA, 1999: 222). A impressão negativa do interior do Brasil e dos brasileiros, causada pela viagem, vem reforçada com o argumento de autoridade dos padres: os sertões são "pedaços do purgatório".

As ruínas estão presentes nos diversos relatos de viagens de estrangeiros e nacionais que percorreram os antigos caminhos que levam ao norte de Goiás no século XIX. De acordo com Maia, os estrangeiros vinham ao Brasil na expectativa de confirmar “certas teorias científicas e animados por uma perspectiva de carreira científica. Os objetivos de coleta de informações [...] somavam-se a uma obsessão pelo registro de sensações e impressões produzidas por uma natureza exótica" (2007: 5). No caso das expedições brasileiras são realizadas "a partir de instituições, academias e órgãos que gravitavam em torno do círculo que agregava política e letras. O Instituto Histórico e Geográfico Brasileiro - o IHGB - é exemplar dessa orientação 'pública' voltada para constituição da identidade brasileira” (MAIA, 2007: 5).

Ao centrar sua análise nas narrativas de dois governadores goianos oitocentista: Couto de Magalhães e Leite Moraes, o referido autor, atenta para a tensão dos administradores diante da magnificência da natureza, suas aspirações modernizantes e a imprevisibilidade e instabilidade das terras interioranas, da qual as ruínas são a prova da trama infindável de empreitadas fracassadas. Enfim, "é constante a visão de ruínas e de vestígios que denotam um mundo instável e aberto, constituído, destruído e reconstituído de forma incessante" (MAIA, 2007: 17).

Murari ressalta que a literatura brasileira da geração de 1870 vê a tapera como um dos aspectos constitutivos e privilegiados da paisagem sertaneja, como "materialização da decadência e, mais ainda, do tempo como instância destruidora, ao revés do progresso" (2009: 233). Na concepção de Neiva e Penna, os homens locais refletem as características do seu ambiente (SÁ, 1999: 41): O jovem literato goiano Hugo de Carvalho Ramos afirma que é comum no interior considerar a "tapera" lugar mal-assombrado (1950: 16).

\footnotetext{
${ }^{9}$ Neiva e Penna associaram os sertões à obra clássica de Dante Alighieri “A Divina Comédia”. Uma trilogia onde o autor imagina uma viagem além-túmulo passando pelo inferno, purgatório e chegando ao céu.
} 
Casas e casarões abandonados pelos homens tornam-se, no imaginário popular, moradas de almas penadas. Para os médicos, elas são sinal de decadência do ambiente e dos próprios homens. Enfim, é como se os homens assim como a natureza tivessem "vocação" para regredir.

A estratégia narrativa de Neiva e Penna amplia a presença e a gravidade da doença de Chagas entre as populações rurais. Assim, o registro do "real" não se dá aleatoriamente. Neiva e Penna, influenciados pelas leituras dos viajantes estrangeiros do século XIX e pela primeira caracterização da doença de Chagas, ficam chocados com o que afirmam terem visto. Para eles, a falta de conservação dos prédios, a precariedade do comércio, mas, principalmente, o aspecto físico dos homens é assustador. Eles avaliam que todos os moradores estão atacados pela doença de Chagas nas suas modalidades crônicas e denunciam, exemplarmente, que a destruição operada pelo tempo atingiu cruelmente as pessoas. Naquele antigo centro de esplendor e riquezas, nada é passível de admiração porque tudo ali está em degradação, sofrendo os efeitos destrutivos do tempo (MURARI, 2009: 235). Assim, não é de se estranhar que em meio a tanta "decadência" aparecem apenas dois homens "aparentemente sadios" apesar de papudos, de quem os médicos conseguem arrancar informações mínimas sobre o caminho a seguir (NEIVA \& PENNA, 1999).

Neiva e Penna encontram obstáculos para compreender o grupo visitado. Incompreensão com relação à língua e ao modo de viver, já que os sertanejos estão inseridos numa outra temporalidade. A singularidade das experiências da população do interior de Goiás é vista negativamente, já que os olhares dos médicos estão direcionados para denunciar a presença generalizada da doença de Chagas, a precariedade técnica e a preguiça dos sertanejos. A expectativa está relacionada ao futuro: eles sonham com cidades e vilas saneadas, com uma agricultura moderna amplamente integrada ao mercado pondo fim aos "sistemas antiquados" da agricultura familiar e das condições de vida "primitivas" no campo. Para isso, eles acreditam ser necessário um sistema de saúde pública centralizado no governo federal, no qual ocupem posições de poder, porque se eles sabem "diagnosticar” os males do Brasil, eles também estão qualificados para ajudar a superá-los.

A viagem permite a Neiva e Penna ver, escutar e transformar a experiência em narrativa. Os referidos "médicos viajores", ao elaborar um relato científico, de acordo com Dominichi de Sá, optam pela pretensa neutralidade e transparência em relação à "verdade", eles "acabaram por entrever a transmutação da natureza e de seu desenho em 
ruínas e desmoronamento" (1999: 42). Logo, em várias partes da narrativa os médicos contestam a inexistência das riquezas naturais e concluem que, naquele "purgatório", comprovadamente, elas não estão presentes.

Neiva e Penna ressaltam o fato de o sertanejo não conhecer o dinheiro do país, desconhecer os símbolos nacionais e identificar apenas os símbolos do catolicismo “popular”. "A única bandeira que conhecem é a do Divino" (NEIVA \& PENNA, 1999: 191). Ele não saberia o valor monetário da moeda em réis, nem o sistema métrico decimal e continua utilizando medidas antigas como o palmo, côvado, vara e onça (NEIVA \& PENNA, 1999: 171). O quilo fora popularizado, porém, para as grandes quantidades a referência continua sendo a arroba. Para as longas distâncias, é a légua, porém, existe a légua grande e a pequena: "a grande quase nunca ultrapassa de 4 quilômetros, por isso as informações concernentes à distância a percorrer, são às vezes das mais disparatadas" (NEIVA \& PENNA, 1999: 171). Enfim, os sertanejos, além de pobres, nômades, famintos, indolentes e ignorantes ainda aparecem como uma ameaça para a nação brasileira, do presente e do futuro.

Significativamente, o que está em questão é uma dada concepção de nação que implica o sentimento de integração, de pertencimento a algo maior do que a própria comunidade local. Para Neiva e Penna, é perceptível a ausência de qualquer identificação do sertanejo com a pátria, o sertão é distante porque sem a presença efetiva do Estado. Distante devido à falta de uma representação cartográfica nos mapas da época, sem um sistema de transportes e comunicações modernas, bem como na inexistência ou ineficácia das escolas públicas existentes. Esse "distante" é também marcado pela diferença com relação ao centro, o litoral. Nesse sentido, a instrução é tida como de fundamental importância na unificação do país. Porém, um Estado laico necessita de uma escola pública. Certamente, o modelo de descentralização da instrução pública para os municípios não agradou a Neiva e Penna.

Na construção narrativa de Neiva e Penna, Goiás também é distante devido à dificuldade de acesso a produtos essenciais e pela manutenção do arcaico. Em geral, no norte de Goiás, segundo Neiva e Penna, o sal é pouco utilizado, devido aos exorbitantes preços cobrados, bem como o café, a aguardente e o querosene. Todavia, o uso de candeia é generalizado, feita de argila e alimentada com óleo de animal, mamona ou cera de abelha ou carnaúba (NEIVA \& PENNA, 1999: 165). O pilão ainda ocupa o lugar do moinho de café. O sertanejo não utiliza o filtro de barro para filtrar água, a máquina de costura era repelida ou desconhecida (NEIVA \& PENNA, 1999; 173). Não se utilizam 
tulhas para guardar milho e feijão. A farinha de mandioca é feita em toda parte, mas o pão é desconhecido fora das cidades e vilas maiores (NEIVA \& PENNA, 1999; 174). Na verdade, durante todo o trajeto da expedição científica pelo interior do norte e do nordeste, o pão só foi encontrado em Juazeiro e em Porto Nacional (NEIVA \& PENNA, 1999: 213).

As condições de vida no interior do Brasil são apresentadas como extremamente precárias. Assim, o vestuário é rudimentar: “As crianças de ambos os sexos das famílias mais pobres, andam nuas mesmo quando já estão bem crescidas, os adultos vivem andrajosamente" (NEIVA \& PENNA, 1999: 167). Os pobres usam roupas de chitas e calças de algodão, fiado, tecido (no tear) e costurado a máquina ou a mão (NEIVA \& PENNA, 1999: 167). Homens, mulheres e crianças pobres vivem com os pés descalços (NEIVA \& PENNA, 1999). Holanda ressalta que fora dos lugares povoados e mesmo nas imediações das vilas e cidades, durante o período colonial, é lícito supor que o calçado fosse considerado supérfluo. Apenas "ao entrar nas vilas é que o caminhante tinha o cuidado de calçar-se, depois de limpar cuidadosamente os pés, para livrar-se dos bichos e da poeira" (HOLANDA, 1994: 28).

Na evocação do "efeito de verdade" que o relato científico quer construir, o narrador registra sua indignação frente à situação de "profunda miséria e do abandono em que jazem milhares de seres humanos" (NEIVA \& PENNA, 1999; 165). Os sertanejos estão presos a formas de viver e sentir de "três séculos atrás", e essa distância cultural entre o litoral e os sertões foi estabelecida por Euclides da Cunha e repetida por Neiva e Penna. Trafega-se por caminhos, chamados de trilhos transitados pelo homem, pelo cavalo e pelas compridas fileiras de burros cargueiros (PEREGRINO, 1942: 13). O transporte de cargas se faz por meio de muares e os animais não são ferrados (NEIVA \& PENNA, 1999: 171).

Enfim, ao acompanhar a viagem (diário de viagem) e a transformação daquela experiência vivida em reflexão científica (relatório), é possível perceber que alguns traços negativos foram sublinhados para reforçar os argumentos que os médicos queriam provar. Nísia Trindade, ao tentar definir os cientistas, conclui que eles podem ser vistos como "os etnógrafos em seu contato e observação do outro, portador de outra cultura e identificado com outras civilizações” (LIMA, 1999: 104). Não poderia ser diferente, pois foi a partir dos seus referenciais culturais, de sua formação e inclusão em determinado "campo" e num determinado momento, que Neiva e Penna ressaltaram certas imagens de Goiás e dos seus habitantes, além de proporem alternativas para a integração nacional. 


\section{O "saneamento do Brasil": o paraíso possível?}

Por iniciativa própria aqueles habitantes serão incapazes de sair da grande pobreza em que vivem, o espírito de iniciativa é pequeno, e esse mesmo, anula-se diante do isolamento em que jazem (NEIVA \& PENNA, 1999: 181).

Sem o concurso da imigração será difícil galvanizar populações rotineiras (NEIVA \& PENNA, 1999: 175).

O relatório de Neiva e Penna coloca em evidência não só o estado "mais central e desconhecido do Brasil”, mas também o próprio “campo médico”. Após uma viagem de sete meses, entre março e outubro de 1912, depois de percorrer cerca de $4.000 \mathrm{~km}$ pelo interior do país, Neiva e Penna proporcionam à Fundação Oswaldo Cruz a ampliação de seu saber sobre o saneamento do interior. Eles qualificam a instituição e o "campo" médico para ser o interlocutor privilegiado desse debate. Eles fornecem "imagens" do interior que se queria superar, além de profissionais, diagnósticos e prognósticos específicos para a construção do "novo homem" e do "novo país".

Certamente, o projeto de saneamento é acompanhado de uma preocupação com o controle social através de um novo modelo de Estado. Saúde, educação e transportes são considerados de fundamental importância e devem ser assumidos pelo poder público. Políticas imigratórias devem ser pensadas para possibilitar a entrada de inovações técnicas na agricultura. Eles sugerem ainda a instalação de postos sanitários e a inadiável necessidade de distribuição de sais de quinino para os sertanejos. Enfim, o federalismo da Constituição de 1891 estava sendo colocado em questão.

Para os referidos médicos, a construção da nação passa também pela transferência da capital para o Planalto Central. Eles defendem a construção de um amplo plano ferroviário, que coloque todos os estados em comunicação com a nova capital. Tal projeto poria fim à dispersão, além de possibilitar a chegada do "progresso" a novos ambientes espaciais e sociais brasileiros. As ideias sobre saneamento, presentes no relatório Neiva e Penna, são ampliadas e publicadas em linguagem mais militante e combativa por Belisário Penna.

A criação da liga pró-saneamento do Brasil, em 1918, sob a liderança de Belisário Penna, tem por objetivo a institucionalização de uma política nacional de saneamento. Os integrantes desse movimento responsabilizam o pacto federativo como um dos grandes responsáveis pela precariedade das condições de salubridade e abandono dos sertanejos 
e como um sério entrave à solução dos problemas brasileiros. Todavia, a centralização da saúde encontra fortes opositores tanto entre as autoridades e lideranças locais, quanto junto aos liberais e ainda junto a uma parte do Legislativo federal. Porém, mesmo assim, os sanitaristas conseguem impor a ideia de centralização como questão relevante na agenda nacional. A chegada da gripe espanhola, em 1918, contribui para a vitória dos sanitaristas. Em 1920, é criado o Departamento Nacional de Saúde Pública.

Belisário Penna defende que a incorporação da população rural à nação se faria pela adoção de novas práticas higiênicas. Os brasileiros do interior devem aprender a alimentar-se, a beber água limpa, a defender-se dos insetos e parasitas transmissores e causadores de doenças; além de perceber as vantagens e necessidades do calçado, de lavar as mãos antes das refeições e depois das defecções; de utilizar-se de fossas e latrina, de abster-se de bebidas alcoólicas. Os sertanejos devem ser instruídos a construir casas higiênicas, iluminadas e com paredes lisas, pintadas ou caiadas e cobertas com telhas. A adoção dessas novas práticas higiênicas implicaria o rompimento com antigos preceitos, qualificados de negligentes, imprudentes e ignorantes (PENNA, 1923: 160-348).

Neiva e Penna apresentam os problemas encontrados no percurso da viagem e apontam suas soluções. Eles conseguem mobilizar a grande imprensa da época acerca de um país praticamente desconhecido e criticam a ineficiência do Estado, sobretudo no que diz respeito à saúde, educação, habitação e transportes no interior do país. Kropf e Lima (2012: 94), ao tratarem da doença de Chagas e do movimento sanitarista na década de 1910, ressaltam a legitimidade adquirida pelos médicos sanitaristas e os conflitos daí advindos. A máxima projeção assumida "por Carlos Chagas e pela triponossomíase americana no domínio da política, ao mesmo tempo em que expressava e gerava reconhecimento e legitimidade, impunha maior susceptibilidade a críticas, controvérsias e tensões". Assim, a "doença do Brasil" tanto é utilizada para justificar o "brado dos sanitaristas" quanto se transforma no centro de uma intensa polêmica na Academia Nacional de Medicina, entre 1922 e 1923 (KROPF \& LIMA, 2012: 94).

De qualquer forma, o intenso debate revela a existência de disputas entre os médicos/cientistas da época, enquanto alguns defendem, outros negam o diagnóstico do "Brasil imenso hospital" (KROPF \& LIMA, 2012: 95). Ele também coloca em cena a desconfiança dos liberais com relação à centralização do poder e a reação das oligarquias regionais às medidas centralizadoras. 


\section{Considerações finais}

Enfrentei o desafio de repensar as fronteiras que separavam os brasileiros, em especial, as relações dicotômicas entre litoral e o sertão. Elas estão presentes no relatório Neiva e Penna, eles queriam provar a tese do Brasil como "imenso hospital", lugar da preguiça e espaço abandonado pelos poderes públicos. A partir dessa realidade eles elaboraram seu projeto de "saneamento dos sertões" que passava, enfim, pela superação das especificidades regionais em função da construção da identidade nacional.

Os equívocos dos olhares e dos ouvidos de Neiva e Penna reforçam as teorias caras ao pensamento cientificista e darwinista da época de que o atraso moral e material da população sertaneja seria decorrência "natural" da sua humanidade inviável. E “inviável”, porque doentes, atrasados, abandonados e "impermeáveis ao progresso" (NEIVA \& PENNA, 1999: 173). Enfim, essas imagens negativas cumprem sua função pedagógica de ensinar a interpretá-las a partir do referente do litoral, ou seja, de como deveria ser o brasileiro do interior e quem deveria ensinar o caminho para construir uma nação moderna, destituindo os sertanejos (as) do protagonismo histórico (MUNIZ, 2011: 30).

Não se pode perder de vista que toda autoria é menos individual e original pois é uma prática cultural. Nesse sentido, faz-se necessário levar em consideração os dispositivos de controle presentes na seleção, abordagem, construção e avaliação dessas narrativas pelo lugar/instituição que o tornam possível. Certeau (1982), ao refletir sobre a escrita da história, seus problemas, desafios e possibilidades, adverte para a irredutibilidade da "prática" ao "texto", tendo em vista que as regras que presidem as práticas são distintas e, por vezes, opostas às que presidem a escrita. Assim, o referido autor aponta para a impossibilidade da escrita de "esgotar" e "dar fim" à totalidade das experiências e práticas culturais. Na condição de prática social controlada pelo conjunto de práticas da qual resulta, o texto confere, ao seu autor e a seus leitores, lugares bem determinados, visto que o primeiro toma para si a tarefa e competência de (re) distribuir referências simbólicas, cabendo aos últimos se apropriar delas.

Ao levar em consideração o lugar institucional ocupado pelos sujeitos que escrevem e que exigem a escrita, percebe-se a existência de uma rede complexa de diálogo dos referidos narradores com autores nacionais e estrangeiros presentes no relatório. Neiva e Penna, além de serem formados pelas duas faculdades de medicina mais 
tradicionais do Brasil, a do Rio de Janeiro e a de Salvador, tiveram seu livro publicado por uma das instituições médicas de maior prestígio da época, o Instituto Oswaldo Cruz. Não por acaso, eles buscam inserir o seu relato no campo científico contra as narrativas literárias da época. Por fim, ao ser instituído como "saber competente", autorizado pela ciência médica, propõe um projeto de intervenção social, o saneamento, que implica obter e manter legitimidade científica, política e social para os médicos e, consequentemente, o desalojamento de outras leituras e outros projetos para o interior do país.

Enfim, as imagens de Neiva e Penna sobre os brasileiros do interior expressam, como não poderia deixar de ser, a visão de mundo daqueles que observam, selecionam e interpretam. Assim, muito embora suas informações e impressões carreguem os argumentos da cientificidade e presumida neutralidade em prol da ampliação do conhecimento sobre os brasileiros do interior, trata-se de mapeamento elaborado sob a referência do ideário civilizador e pautado no ideal de identidade nacional, uma narrativa comprometida com um "campo" e com um tempo específico.

\section{Fontes}

CUNHA, Euclides (2005). Os Sertões: Campanha de Canudos. São Paulo: Martins Claret. NEIVA, Arthur \& PENNA, Belisário (1999). Viagem Científica Pelo Norte da Bahia, Sudoeste de Pernambuco, Sul do Piauí e de Norte a Sul de Goiás. Ed. Fac-similar. Brasília: Senado Federal.

PENNA, Belisário (1923). Saneamento do Brasil. Sanear o Brasil é povoal-o; é enriquecel-o; é moralisal-o. 2 ed. Rio de Janeiro: Jacinto Ribeiro dos Santos.

\section{Referências Bibliográficas}

ALVES, Fernando A. Pires \& MELlO, Maria Teresa Villela Bandeira de (2009). Expedições científicas, fotografia e intenção documentária: as viagens do Instituo Oswaldo Cruz (1911-1913). História, Ciências, Saúde-Manguinhos. Rio de Janeiro, vol.16,supl.1. jul., pp.139-179.

BOURDIEU, Pierre (2007). O Poder Simbólico. 11 ed. Rio de Janeiro: Bertran Brasil.

CERTEAU, Michel de (2000). A escrita da História. 2 ed. Rio de Janeiro: Forense Universitária.

ELIAS, Norbert (1994). O Processo Civilizador. Rio de Janeiro: Zahar.

HATOG, François (1999). O espelho de Heródoto: ensaios sobre a representação do Outro. Belo Horizonte: UFMG.

HERSCHMANN, Micael (1996). Entre a insalubridade e a ignorância. A construção do campo médico e do ideário moderno no Brasil. In: HERSCHMANN, Micael. KROPF, Simone. NUNES, Clarice (Orgs.). Missionários do progresso. Médicos, 
engenheiros e educadores no Rio de Janeiro 1870-1937. Rio de Janeiro: Diadorim, pp.11-67.

HOCHMAN, Gilberto (1998). Logo ali, no final da avenida: Os Sertões redefinidos pelo movimento da Primeira República. História, Ciência e Saúde: Manguinhos. vol. V, supl., jul., pp. 217-235.

HOLANDA, Sérgio Buarque de (1994). Caminhos e fronteiras. São Paulo: Cia das Letras.

(1995). Raízes do Brasil. 26 ed. São Paulo: Cia das Letras.

KOSELLECK, Reinhart (2006). Espaço de Experiência e Horizonte de Expectativa: duas categorias históricas. In: KOSELLECK, Reinhart. Futuro do Passado. Contribuição à semântica dos tempos históricos. Rio de Janeiro: Contraponto, pp.305-327.

KROPF, Simone Petraglia (2009). Carlos Chagas e os debates e controvérsias sobre a doença do Brasil (1909-1923). História, Ciências, Saúde-Manguinhos. [online]. Vol. 16, supl.1. Rio de Janeiro, jul., pp.203-277. (2006). Doença de Chagas, doença do Brasil: ciência, saúde, nação (1909-1962). Tese (Doutorado em História). Universidade Federal Fluminense, Niterói, RJ.

LACERDA, Aline Lopes de (2009). Fotografia e valor documentário: o arquivo de Carlos Chagas. História, Ciências, Saúde-Manguinhos. Rio de Janeiro, vol.16, supl. 1, jul., pp.115-138.

LE GOFF, Jacques (1996). Documento/monumento. In: LE GOFF, Jacques. História e Memória. 4 ed. São Paulo: UNICAMP, pp.525-545.

LEITE, Míriam Moreira (1997). Livros de Viagem (1803-1900). Rio de Janeiro: EdUFRJ.

LIMA, Nísia Trindade (1999). Um Sertão Chamado Brasil. Intelectuais, sertanejos e imaginação social. Tese de doutorado em sociologia. Rio de Janeiro: IUPERJ, 1999. (1998). Missões civilizatórias da República e interpretações do Brasil. História, Ciências, Saúde-Manguinhos. vol V, suplemento, jul., pp.164-188.

(2009). Uma brasiliana médica: o Brasil Central na expedição científica de Arthur Neiva e Belisário Penna e na viagem ao Tocantins de Júlio Paternostro. História, Ciências, Saúde-Mnaguinhos. vol 16, supl.1. Rio de Janeiro, jul., pp.229-248.

LIMA, Nísia Trindade \& KROPF, Simone Petráglia. A doença de chagas e o movimento sanitarista na década de 1910. In: PONTE, Carlos Fidelis; LIMA, Nísia Trindade; KROPF, Simone Petraglia (orgs). O sanitarismo (re)descobre o Brasil. pp. 79-95. Disponível

em: http://www.observatorio.epsjv.fiocruz.br/upload/na\%20corda\%20bamba/cap_3.pd f. Acesso: 08 dez. 2016.

MAIA, João Marcelo Ehlert (2007). Governadores de ruínas: os relatos de viagem de Couto de Magalhães e Leite Moraes. Estudos Históricos, Rio de Janeiro, n. 40, jul.dez., pp.3-23.

MELLO, Ceres Rodrigues (1987). O sertão nordestino e suas permanências (séc. XVIXIX). Revista do Instituto Histórico e Geográfico Brasileiro. Rio de Janeiro, vol. 148, n. 356, jul/set., pp.283-311.

MELLO, Maria Tereza Villela \& PIRES-ALVES, Fernando (2009). Expedições científicas, fotografia e intenção documentária: as viagens do Instituto Oswaldo Cruz (1911-1913). História, Ciência, Saúde-Manguinhos. Rio de Janeiro, vol. 16. supl. 1. jun., pp.115-138.

MOREYRA, Sérgio Paulo (1987/88). O olho que vê o mundo. Boletim Goiano de Geografia. vol. 7 e 8, n. 1 e 2. jan/.dez. 
MUNIZ, Diva do Couto Gontijo (2004). Sobre experiências, cultura escolar e identidades. In: SERPA, Elio et all. (Orgs.). Escritas da história: intelectuais e poder. Goiânia: UCG, pp.83-98.

(2011). O refrão da Nação/Civilização e uma dupla sertaneja: viajantes estrangeiros e o interior do Brasil Oitocentista. In: MUNIZ, Diva do Couto Gontijo e SENA, Ernesto Cerqueira. Nação, civilização e história: leituras sertanejas. Goiânia: EdPUC, pp.21-40.

MURARI, Luciana (2009). Natureza e cultura no Brasil (1870-1922). São Paulo: Alameda.

RAMOS, Victor de Carvalho (2001). Um mundo desconhecido. A Informação Goyana, ago.1917, Goiânia: AGEPEL, pp. 9-10. (CD-ROM).

SÁ, Dominichi Miranda de (1999). O Brasil "Modelado" na Obra de Belisário Penna (1916-1935). Dissertação (Mestrado em História Social). Universidade Federal do Rio de Janeiro, Rio de Janeiro.

(2003). Idéias sem fronteira: da generalidade à especialização no pensamento intelectual do Brasil Republicano (1985-1935). Tese (Doutorado em História Social). Universidade Federal do Rio de Janeiro, Rio de Janeiro.

(2009). Uma interpretação do Brasil como doença e rotina: a repercussão do relatório médico de Arthur Neiva e Belisário Penna (1917-1935). História, Ciência, Saúde-Manguinhos. Rio de Janeiro, vol. 16, supl.1, jul., pp.183-203.

SALGADO, Manuel (2000). Usos da história: refletindo sobre identidade e sentido. História em Revista. Dossié: Historiografia. Pelotas: UFPel, vol. 6, dez., pp.21-36.

SANDES, Noé Freire \& RIBEIRO, José Eustáquio (1991). Nação e região. Goiás no século XIX. Revista Teoria e Práxis. Goiânia, n. 3.

SANDES, Noé Freire (2002). Memória e História de Goiás. In: SANDES, Noé Freire (Org). Memória e Região. Brasília: Ministério da Integração Regional, pp.17-36.

SEVCENKO, Nicolau (2003). Literatura como missão. Tensões sociais e criação cultural na Primeira República. 2 ed. São Paulo: Cia das Letras.

(1998). Introdução. Prelúdio republicano, astúcias da ordem e ilusões do progresso. In: SEVCENKO, Nicolau (Org.). História da vida privada no Brasil. Vol. 3. pp.7-48.

SOUZA, Vanderlei Sebastião de (2009). Arthur Neiva e a 'questão nacional' nos anos 1910 e 1920. In: História, Ciências, Saúde-Manguinhos. Rio de Janeiro, vol.16, supl.1, jul., pp. 249-264

SÜSSEKIND, Flora (1990). O Brasil não é longe daqui: o narrador, a viagem. São Paulo: Cia das Letras.

Artigo recebido em 30 de agosto de 2016.

Aprovado em 27 de novembro de 2016. 